\title{
IP6K2 predicts favorable clinical outcome of primary breast cancer
}

\author{
JOSEFINE SANDSTRÖM ${ }^{1}$, ALIEN BALIAN ${ }^{1}$, REBECCA LOCKOWANDT ${ }^{1}$, TOMMY FORNANDER ${ }^{2}$, \\ BO NORDENSKJÖLD ${ }^{1}$, LINDA LINDSTRÖM ${ }^{3}$, GIZEH PÉREZ-TENORIO ${ }^{1}$ and OLLE STÅL ${ }^{1}$ \\ ${ }^{1}$ Department of Biomedical and Clinical Sciences and Department of Oncology, Linköping University, \\ 58183 Linköping; ${ }^{2}$ Department of Oncology-Pathology, Karolinska Institute, 17176 Stockholm; \\ ${ }^{3}$ Department of Biosciences and Nutrition, Karolinska Institute, 14183 Stockholm, Sweden
}

Received October 9, 2020; Accepted February 9, 2021

DOI: $10.3892 / \mathrm{mco} .2021 .2256$

\begin{abstract}
The inositol hexakisphosphate kinase (IP6K) 1 and 2 genes are localized at $3 \mathrm{p} 21.31$, a highly altered gene-dense chromosomal region in cancer. The IP6Ks convert IP6 to IP7, which inhibits activation of the tumor-promoting $\mathrm{PI} 3 \mathrm{~K} / \mathrm{Akt} / \mathrm{mTOR}$ signaling pathway. IP6K 2 has been suggested to be involved in p53-induced apoptosis, while IP6K1 may stimulate tumor growth and migration. The present study aimed to elucidate the role of the two IP6Ks in predicting outcome in patients with breast cancer. To the best of our knowledge, the role of IP6K was analyzed for the first time in tumors from three cohorts of patients with breast cancer; one Swedish low-risk cohort, one Dutch cohort and the TCGA dataset. Analyses of gene -and protein expression and subcellular localization were included. IP6K2 gene expression was associated with ER positivity and nuclear p-Akt. Improved prognosis was detected with high IP6K2 gene expression compared with low IP6K2 gene expression in systemically untreated patients in the Swedish low-risk and Dutch cohorts. In the TCGA dataset, IP6K2 prognostic value was significant when selecting for tumors with wild-type TP53. A multivariable analysis testing IP6K2 against other cancer-related genes at 3p.21.31, including IP6K1 and clinical biomarkers, revealed that IP6K2 was associated with decreased risk of distant recurrence. IP6K1 was associated with increased risk of distant recurrence in the multivariable test and protein analysis revealed trends of worse prognosis with high IP6K1 in the cytoplasm. The expression levels of IP6K1 and IP6K2 were associated to a high extent; however, a diverging prognostic value of the two genes was observed in breast cancer. The
\end{abstract}

Correspondence to: Dr Josefine Sandström, Department of Biomedical and Clinical Sciences and Department of Oncology, Linköping University, Lasarettsgatan, Building 463, Campus US, 58183 Linköping, Sweden

E-mail: josefine.sandstrom@liu.se

Key words: inositol hexakisphosphate kinase 1, PI3K/Akt/mTOR pathway, TP53, Akt, 3p21.31, prognosis present data suggest that IP6K2 can be a favorable prognostic factor, while IP6K1 may not be.

\section{Introduction}

The PI3K-Akt-mTOR pathway is one of the most frequently altered signaling cascades in breast cancer (1). This pathway is targeted in several clinical studies (2). The inositol pyrophosphate (IPP) IP7 is a small phosphate-rich regulator of Akt, inhibiting membrane translocation and activation of Akt by competing with membrane-bound phosphoinositide binding to the pleckstrin homology domain, and thereby disturbing the pyruvate dehydrogenase kinase 1 (PDK1) -induced phosphorylation at the Akt-threonine 308 site $(3,4)$. The inositol hexakisphosphate kinases (IP6K) 1 and 2 are responsible for the conversion of IP6 to IP7 (5).

The IP6K1 and IP6K2 genes are localized at the chromosomal site $3 \mathrm{p} 21.31$, which is a gene-dense region, including several putative tumor suppressor genes and some oncogenes $(6,7)$. In the context of Akt inhibition, the IP6Ks would play a tumor suppressive role as Akt inhibition slows down tumor proliferation and increases apoptosis (8). Deletion and knock-out studies have found diverging roles of isoforms of the two IP6Ks in tumors and between different phases of tumor progression. IP6K1 has been suggested to be an oncogene, stimulating early cytoskeletal changes, migration and tumor growth (9), whereas IP6K2 has been suggested to hold tumor suppressive features by inducing apoptosis in a p53-dependent manner $(10,11)$. IP6K2 was important for the response to radiation and cytotoxic drugs in ovarian carcinoma cells, and loss of IP6K2 predicted higher prevalence of aero-digestive carcinoma in mice fed with a carcinogen $(12,13)$.

We have previous data indicating that other factors in the $\mathrm{PI} 3 \mathrm{~K} / \mathrm{Akt} / \mathrm{mTOR}$ pathway are altered in the Swedish low-risk breast cancer cohort (14-16). IP6Ks have been found in vitro to indirectly, through IP7, inhibit Akt. The hypothesis was that the IP6K would inhibit the PI3K/Akt/mTOR pathway and be protective factors in breast cancer. Therefore, in this study we evaluated the role of IP6K1 and IP6K2 by analyzing their impact on outcome in three separate cohorts of patients with primary breast cancer. Analyses of gene expression, protein expression and subcellular localization of proteins 
were included. To our knowledge, the IP6Ks have never been evaluated in cancer patient cohorts, hence this is the first study in this respect.

\section{Materials and methods}

Swedish low-risk cohort. Postmenopausal breast cancer patients at low risk, with a negative node status and a tumor not exceeding three $\mathrm{cm}$ were randomized to adjuvant tamoxifen, $40 \mathrm{mg} /$ day for two years or no tamoxifen (17). Patient entry to the studies was from November 1976 to May 1990, and follow-up data was available to December 2004. In 1983, tamoxifen-treated recurrence-free patients were randomized, if consenting, to three more years of tamoxifen or no tamoxifen. Patients were mainly of Caucasian ethnicity, and all female. Median age at diagnosis was 62.7, ranging from 45.8 to 76.8 . Retrospective studies on archived tumor tissue, with the purpose to evaluate prognostic and treatment predicting factors, were approved by the ethics committee at Karolinska Institute in Stockholm, Sweden. Tumor tissue was collected on surgical removal of the primary tumor and incubated in formalin for fixation and paraffin embedded. Three cores of abundant cancer cell content were selected to represent each tumor on a tissue microarray (TMA). The ER, progesterone receptor $(\mathrm{PgR})$ and HER2 status were assessed as previously described $(18,19)$. Further data on p-Akt and p-S6K were available $(14,16)$. For all proteins detected, a portion of samples was missing. In the supplementary table of a previously published paper, missing samples were compared with the samples on TMA and with samples of the original cohort (20). The results show no bias in the missing cases with respect to tumor size, ER status, or tamoxifen treatment. The present study was designed and presented with regard to the reporting recommendations for tumor marker prognostic studies (REMARK) guidelines (21).

Online datasets. Gene-expression data was drawn from a Dutch retrospective publicly available dataset of 295 breast cancer patients with a tumor not exceeding five $\mathrm{cm}$ at stage I and II, including node-negative -and node-positive disease (22). Time for diagnosis was during 1984 and 1995, including patients up to the age of 52. Patients were diagnosed in the Netherlands and were at diagnosis 52 years or younger. Follow-up time, treatment regimens and gene-expression data were downloaded from http://bioinformatics.nki.nl/data.php. Additional data used for analysis was available through personal communication.

Further, prognostic impact of IP6K1 and IP6K2 gene expression was tested in an additional breast cancer cohort, the Cancer Genome Atlas (TCGA), previously described (23), and accessed through cBioPortal for Cancer Genomics https://www.cbioportal.org/ (24). Patients in the TCGA cohort were both pre-and postmenopausal. Twelve patients were male. Median age was 58, ranging from 26 to 90 . Ethnicity distribution was previously published (25).

Expression of genes at 3p21.31. Formalin fixed and paraffin embedded (FFPE) tumors from 912 women in the Swedish low-risk group were retrieved. Messenger RNA was later extracted from FFPE breast tumor tissue and 652 samples were available for microarray gene-expression analysis using custom-designed arrays, containing approximately $32.1 \mathrm{~K}$ probes, detecting approximately $21.5 \mathrm{~K}$ unique genes (Agilent Technologies, CA, USA) (26). The PAM50 intrinsic subtype analysis classifier was used as described in Parker et al (27). Expression levels of IP6K1 and IP6K2 were analyzed by quartiles with low expression defined by the first quartile (Q1). High expression was defined by the second to fourth quartile (Q2-Q4).

The $I P 6 K$ genes are localized in a gene-dense region. We found six cancer-related genes near the IP6Ks at 3p21.31. SETD2, PTPN23, PLXNB1 and RASSF1 are potential tumor-suppressor genes and $C D C 25 \mathrm{~A}$ and $R H O A$ are predicted oncogenes according to their function in tumor cells. The prognostic value of the selected $3 \mathrm{p} 21.31$ genes was analyzed in quartiles of gene expression, as with the IP6Ks. The cut-off for low expression was set at Q1.

Immunohistochemical staining of IP6K1 and IP6K2 proteins. Immunohistochemical analysis was used to detect IP6K1 protein expression in 731 samples and IP6K2 protein expression in 724 samples from the Swedish low-risk group. Staining was evaluated at $\mathrm{x} 400$ magnification by two independent observers (J.S. and A.B.). Cytoplasmic protein expression was evaluated as negative, weak staining, moderate and strong staining, Fig. S1A-H). For analysis of cytoplasm in two groups, negative and weak were set as low, whereas moderate and strong were regarded as high. Nucleus was graded as positive when $>10 \%$ of tumor cells showed staining. The PT-link station was used for deparaffinization and antigen retrieval in a low-pH buffer, starting at $65^{\circ} \mathrm{C}, 96^{\circ} \mathrm{C}$ for $20 \mathrm{~min}$ and cooled down to $65^{\circ} \mathrm{C}$ (DakoCytomation, Glostrup, Denmark). Inactivation of endogenous peroxidase in $3 \%$ hydrogen peroxide in water was followed by blocking in serum-free protein block for $10 \mathrm{~min}$ (Spring Bioscience). TMAs were incubated in a moisturized chamber at $4^{\circ} \mathrm{C}$ overnight with the IP6K1 and IP6K2 antibodies, diluted 1:800 and 1:500, respectively (IP6K1:HPA040825, RRID:AB_10960426 and IP6K2:HPA007532, RRID:AB_1851542, Merck KGaA). Secondary rabbit antibody (DakoCytomation Envision+ HRP system) was applied for 30 min and protein staining was developed with 3,3'-diaminobenzidine chromogen and substrate buffer (DakoCytomation) and counterstained with hematoxylin. All wash steps were in phosphate buffered saline including $0.5 \%$ bovine serum albumin. The tissue was dehydrated, and cover glass was mounted with Pertex (Histolab). All slides were scanned with ScanScope AT (Aperio) and the images were assessed with Aperio Imagescope software v.12.4.3.

IP6K1 -and IP6K2 antibody validation. Antibodies were validated by knock-down of the specific genes in breast cancer cell lines (Fig. S2). The cell line ZR751 (RRID:CVCL_0588) was transfected with two IP6K2 siRNAs (1. s224205 and 2. s195221, Ambion by ThemoFisher Scientific, MA, USA) and BT474 (RRID:CVCL_0179) and T47D (RRID:CVCL_0553) were transfected with IP6K1 siRNA (s18957, Ambion by ThemoFisher Scientific). Protein detection with western blotting showed specific bands at the expected $50 \mathrm{kDa}$ that were downregulated after siRNA transfection. All cell lines were transfected with a scrambled siRNA (AllStars Negative Control, 102728, Qiagen) and GAPDH siRNA (4390849, 

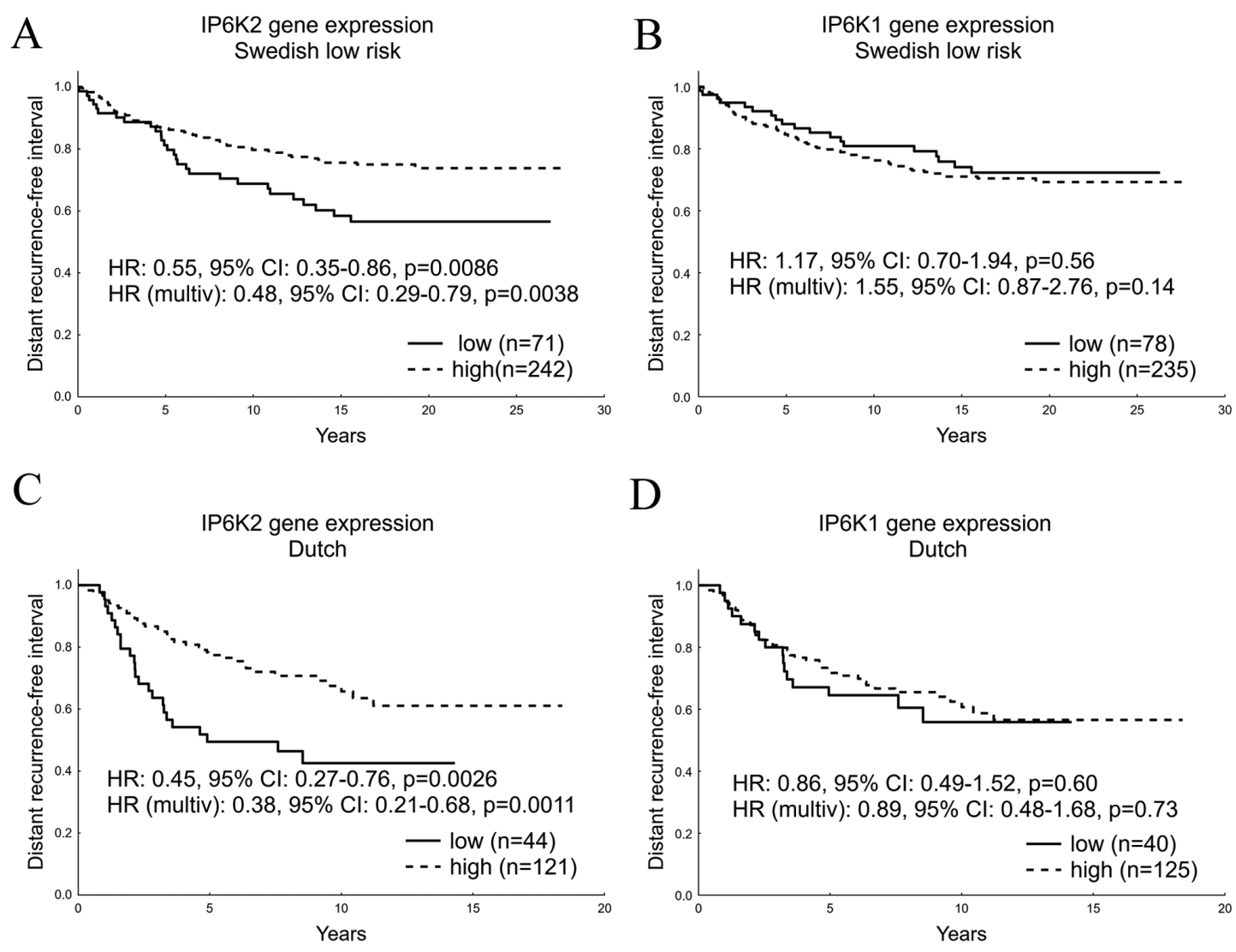

$\mathrm{D}$

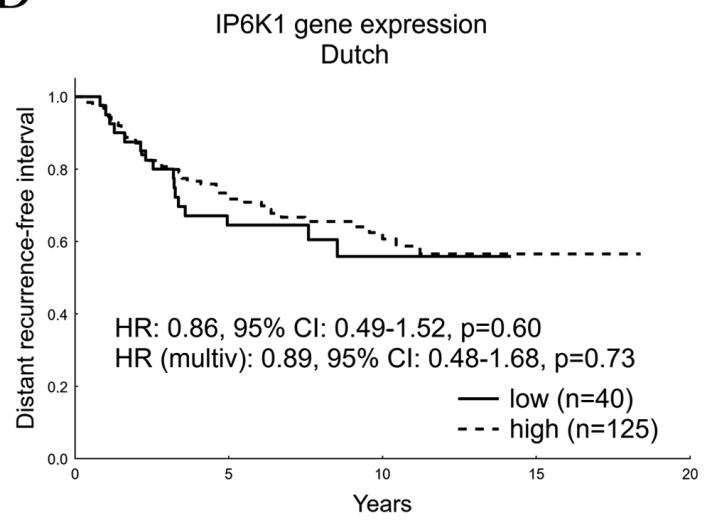

$\mathrm{E}$

$\mathrm{F}$
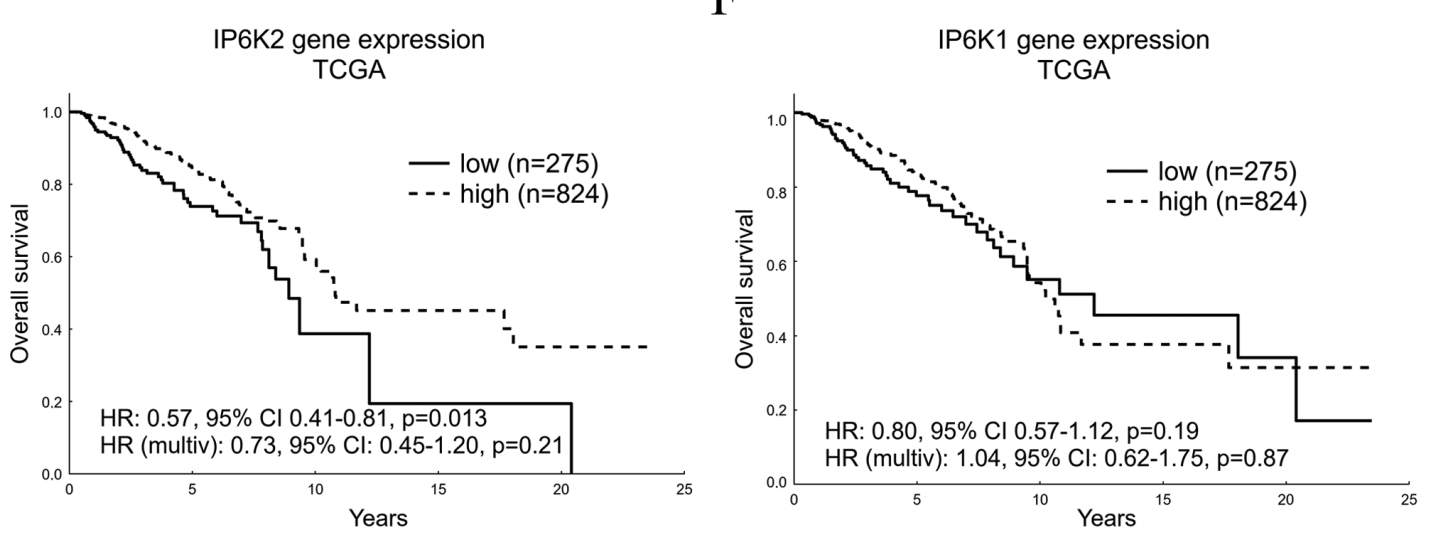

Figure 1. IP6K gene expression as a prognostic biomarker. Gene expression levels of (A) IP6K2 and (B) IP6K1 in the Swedish low-risk cohort with the multivariable Cox proportional hazard model corrected for tumor size, and ER, PgR and HER2 status. Gene expression levels of (C) IP6K2 and (D) IP6K1 in the Dutch cohort with the multivariable model corrected for node, ER and HER2 status. Prognostic data was produced from systemically untreated patients with primary tumors of the two cohorts. Gene expression levels of (E) IP6K2 and (F) IP6K1 in the TCGA cohort with the multivariable model corrected for node, ER, PgR, HER2 and TP53 status. IP6K, inositol hexakisphosphate kinase; ER, estrogen receptor; PgR, progesterone receptor; HR, hazard ratio; TCGA, The Cancer Genome Atlas; multiv, multivariate.

Ambion by Themo Fisher Scientific) and GAPDH antibody (ab185059, Abcam) served as loading control. Cell line passage number was kept low. Cells were regularly confirmed negative for mycoplasma and authenticated by morphology, karyotyping and STR-assay (ATCC).

Statistical analysis. The Kaplan-Meier product limit method was used to estimate the cumulative probabilities of distant recurrence-free interval. For univariable and multivariable analysis of event rates and P-values, Cox proportional hazard regression was used. Associations between different variables were assessed by Pearson $\chi^{2}$ test. P-values $<0.05$ were considered statistically significant. Statistical analyses were performed with Statistica 13.5 (TIBCO Software Inc.).

\section{Results}

Low IP6K2 gene expression predicts impaired prognosis in independent cohorts. The prognostic value of gene-expression levels was tested in the systemically untreated subset of the Swedish low-risk cohort with distant recurrence-free interval as end point. Patients with high IP6K2 expression had a better outcome than patients with low IP6K2 expression (HR: 0.55, 95\% CI: 0.35-0.86, $\mathrm{P}=0.0086$, Fig. 1A). This was confirmed 
Table I. IP6K2 gene and protein expression, clinicopathological variables and PI3K/Akt/mTOR-related variables in the Swedish low-risk cohort.

\begin{tabular}{|c|c|c|c|c|c|c|c|c|c|}
\hline \multirow[b]{2}{*}{ Variables } & \multicolumn{3}{|c|}{ IP6K2 mRNA } & \multicolumn{3}{|c|}{ Cytoplasmic IP6K2 } & \multicolumn{3}{|c|}{ Nuclear IP6K2 } \\
\hline & $\begin{array}{l}\text { Low, } \\
\mathrm{n}(\%)\end{array}$ & $\begin{array}{l}\text { High, } \\
\text { n (\%) }\end{array}$ & P-value & $\begin{array}{l}\text { Low, } \\
\mathrm{n}(\%)\end{array}$ & $\begin{array}{l}\text { High, } \\
\text { n (\%) }\end{array}$ & P-value & $\begin{array}{c}\text { Negative, } \\
n(\%)\end{array}$ & $\begin{array}{c}\text { Positive, } \\
\mathrm{n}(\%)\end{array}$ & P-value \\
\hline \multicolumn{10}{|l|}{ Tamoxifen } \\
\hline No tamoxifen & $71(23)$ & $242(77)$ & & $61(17)$ & $289(83)$ & & $296(85)$ & $54(15)$ & \\
\hline Tamoxifen & $93(27)$ & $247(73)$ & 0.169 & $87(23)$ & $286(77)$ & 0.050 & $315(84)$ & $58(16)$ & 0.964 \\
\hline \multicolumn{10}{|l|}{ Size, mm } \\
\hline$<20$ & $114(23)$ & $386(77)$ & & $116(21)$ & $433(79)$ & & $451(82)$ & $98(18)$ & \\
\hline$>20$ & $47(32)$ & $98(68)$ & 0.019 & $27(17)$ & $131(83)$ & 0.265 & $147(93)$ & $11(7)$ & $<0.001$ \\
\hline \multicolumn{10}{|l|}{ ER } \\
\hline Negative & $47(37)$ & $81(63)$ & & $25(16)$ & $133(84)$ & & $139(88)$ & $19(12)$ & \\
\hline Positive & $112(22)$ & $400(78)$ & $<0.001$ & $121(22)$ & $427(78)$ & 0.087 & $459(84)$ & $89(16)$ & 0.195 \\
\hline \multicolumn{10}{|l|}{$\mathrm{PgR}$} \\
\hline Negative & $74(28)$ & $194(72)$ & & $53(18)$ & $248(82)$ & & $262(87)$ & $39(13)$ & \\
\hline Positive & $74(23)$ & 247 (77) & 0.204 & $81(24)$ & $260(76)$ & 0.056 & $295(87)$ & $46(13)$ & 0.842 \\
\hline \multicolumn{10}{|l|}{ HER2 } \\
\hline Negative & $132(24)$ & $408(76)$ & & $127(22)$ & $461(78)$ & & $494(84)$ & $94(16)$ & \\
\hline Positive & $20(34)$ & $38(66)$ & 0.095 & $10(13)$ & $68(87)$ & 0.072 & $72(92)$ & $6(8)$ & 0.054 \\
\hline \multicolumn{10}{|l|}{ Cyto p-Akt } \\
\hline Negative & $52(24)$ & $164(76)$ & & $71(26)$ & $202(74)$ & & $220(81)$ & 53 (19) & \\
\hline Positive & $106(28)$ & $272(72)$ & 0.292 & $73(17)$ & $354(83)$ & 0.004 & $373(87)$ & $54(13)$ & 0.015 \\
\hline \multicolumn{10}{|l|}{ Nucl p-Akt } \\
\hline Negative & $87(32)$ & $188(68)$ & & $67(22)$ & $237(78)$ & & $272(89)$ & $32(11)$ & \\
\hline Positive & $71(22)$ & $248(78)$ & 0.010 & 77 (19) & $319(81)$ & 0.400 & $321(81)$ & 75 (19) & 0.002 \\
\hline \multicolumn{10}{|l|}{ Cyto p-S6K } \\
\hline Negative & $58(23)$ & $191(77)$ & & $81(27)$ & $215(73)$ & & $247(83)$ & $49(17)$ & \\
\hline Positive & $95(27)$ & $252(73)$ & 0.260 & $63(16)$ & $331(84)$ & $<0.001$ & $340(86)$ & $54(14)$ & 0.299 \\
\hline \multicolumn{10}{|l|}{ Nucl p-S6K } \\
\hline Negative & $110(29)$ & $263(71)$ & & 85 (19) & $352(81)$ & & $380(87)$ & $57(13)$ & \\
\hline Positive & 43 (19) & $179(81)$ & 0.006 & $59(23)$ & $193(77)$ & 0.218 & $206(82)$ & $46(18)$ & 0.065 \\
\hline \multicolumn{10}{|l|}{ PAM50 } \\
\hline Basal like & $25(40)$ & $38(60)$ & & $5(9)$ & $48(91)$ & & $48(91)$ & $5(9)$ & \\
\hline Luminal B & $35(27)$ & $94(73)$ & & $23(20)$ & $90(80)$ & & $105(93)$ & $8(7)$ & \\
\hline HER2 enriched & $21(36)$ & $37(64)$ & & $9(18)$ & $41(82)$ & & $46(92)$ & $4(8)$ & \\
\hline Luminal A & $73(21)$ & 269 (79) & & $55(19)$ & $229(81)$ & & $239(84)$ & $45(16)$ & \\
\hline Normal like & $10(17)$ & $50(83)$ & 0.003 & $11(24)$ & $34(76)$ & 0.377 & $34(76)$ & $11(24)$ & 0.017 \\
\hline
\end{tabular}

Pearson's $\chi^{2}$ test was used. IP6K, inositol hexakisphosphate kinase; PI3K, phosphatidylinositol 3 kinase; Akt, protein kinase B; mTOR, mechanistic target of rapamycin.

in a multivariable analysis (HR: $0.48,95 \% \mathrm{CI}: 0.29-0.79$, $\mathrm{P}=0.0038)$. IP6K1 expression (Q1 vs. Q2-4) showed no significant prognostic value in the univariable analysis $(\mathrm{P}=0.56)$, or in the multivariable analysis correcting for tumor size, ER, PgR and HER2 status ( $\mathrm{P}=0.14$, Fig. 1B). Testing IP6K gene expression in relation to clinicopathological characteristics and PI3K/Akt/mTOR-pathway variables we found IP6K2 gene expression to be associated with small tumor size $(\mathrm{P}=0.019)$, ER $(\mathrm{P}=0.00051)$, nuclear $\mathrm{p}-\mathrm{Akt}(\mathrm{P}=0.0058)$ and nuclear $\mathrm{p}-\mathrm{S} 6 \mathrm{~K}$ $(\mathrm{P}=0.0063)$ and IP6K1 gene expression to be associated with
ER $(\mathrm{P}=0.014)$, nuclear $\mathrm{p}-\mathrm{Akt}(\mathrm{P}=0.0058)$ and with nuclear $\mathrm{p}-\mathrm{S} 6 \mathrm{~K}(\mathrm{P}=0.045)$. In addition, IP6K 2 and IP6K1 expression distribution according to PAM50 intrinsic subtypes are presented (Tables I and II). IP6K1 and IP6K 2 gene expression were strongly associated $(\mathrm{P}<0.00001)$.

A Dutch set available online with gene-expression data on breast tumors from systemically untreated patients together with clinical data was used to test the prognostic value of the IP6Ks in an independent cohort (22). In line with our gene expression results from the Swedish low-risk cohort high 
Table II. IP6K1 gene and protein expression, clinicopathological variables and PI3K/Akt/mTOR-related variables in the Swedish low-risk cohort.

\begin{tabular}{|c|c|c|c|c|c|c|c|c|c|}
\hline \multirow[b]{2}{*}{ Variables } & \multicolumn{3}{|c|}{ IP6K1 mRNA } & \multicolumn{3}{|c|}{ Cytoplasmic IP6K1 } & \multicolumn{3}{|c|}{ Nuclear IP6K1 } \\
\hline & $\begin{array}{l}\text { Low, } \\
\mathrm{n}(\%)\end{array}$ & $\begin{array}{l}\text { High, } \\
\text { n (\%) }\end{array}$ & P-value & $\begin{array}{l}\text { Low, } \\
\mathrm{n}(\%)\end{array}$ & $\begin{array}{l}\text { High, } \\
\text { n (\%) }\end{array}$ & P-value & $\begin{array}{c}\text { Negative, } \\
\mathrm{n}(\%)\end{array}$ & $\begin{array}{c}\text { Positive, } \\
\text { n }(\%)\end{array}$ & P-value \\
\hline \multicolumn{10}{|l|}{ Tamoxifen } \\
\hline No tamoxifen & $78(25)$ & $235(75)$ & & $74(21)$ & $276(79)$ & & $142(41)$ & $208(59)$ & \\
\hline Tamoxifen & $86(25)$ & $254(75)$ & 0.912 & $77(20)$ & $304(80)$ & 0.756 & $173(45)$ & $208(55)$ & 0.187 \\
\hline \multicolumn{10}{|l|}{ Size, mm } \\
\hline$<20$ & $126(25)$ & $374(75)$ & & $120(22)$ & $432(78)$ & & $212(38)$ & $340(62)$ & \\
\hline$>20$ & $36(25)$ & $109(75)$ & 0.927 & $28(17)$ & $135(83)$ & 0.207 & $98(60)$ & $65(40)$ & $<0.001$ \\
\hline \multicolumn{10}{|l|}{ ER } \\
\hline Negative & $43(34)$ & $85(66)$ & & $27(17)$ & $130(83)$ & & $101(64)$ & $56(36)$ & \\
\hline Positive & $118(23)$ & $394(77)$ & 0.014 & $122(22)$ & $431(78)$ & 0.187 & 207 (37) & $346(63)$ & $<0.001$ \\
\hline \multicolumn{10}{|l|}{$\mathrm{PgR}$} \\
\hline Negative & $76(28)$ & $192(72)$ & & 57 (19) & $247(81)$ & & $158(52)$ & $146(48)$ & \\
\hline Positive & $77(24)$ & $244(76)$ & 0.228 & $68(20)$ & $269(80)$ & 0.649 & $123(37)$ & $214(63)$ & $<0.001$ \\
\hline \multicolumn{10}{|l|}{ HER2 } \\
\hline Negative & $132(24)$ & $408(76)$ & & $134(22)$ & $465(78)$ & & $251(42)$ & $348(58)$ & \\
\hline Positive & $20(34)$ & $38(66)$ & 0.095 & $4(5)$ & $72(95)$ & $<0.001$ & $40(53)$ & $36(47)$ & 0.075 \\
\hline \multicolumn{10}{|l|}{ Cyto p-Akt } \\
\hline Negative & $48(22)$ & $168(78)$ & & $98(35)$ & $183(65)$ & & $121(43)$ & $160(57)$ & \\
\hline Positive & $104(28)$ & $274(72)$ & 0.155 & $47(11)$ & $381(89)$ & $<0.001$ & $182(43)$ & $246(57)$ & 0.888 \\
\hline \multicolumn{10}{|l|}{ Nucl p-Akt } \\
\hline Negative & $85(31)$ & $190(69)$ & & $75(24)$ & $240(76)$ & & $182(58)$ & $133(42)$ & \\
\hline Positive & $67(21)$ & $252(79)$ & 0.006 & $70(18)$ & $324(82)$ & 0.047 & $121(31)$ & $273(69)$ & $<0.001$ \\
\hline \multicolumn{10}{|l|}{ Cyto p-S6K } \\
\hline Negative & $53(21)$ & $196(79)$ & & $82(28)$ & $211(72)$ & & $127(43)$ & $166(57)$ & \\
\hline Positive & $95(27)$ & $252(73)$ & 0.090 & $60(15)$ & $337(85)$ & $<0.001$ & $171(43)$ & $226(57)$ & 0.943 \\
\hline \multicolumn{10}{|l|}{ Nucl p-S6K } \\
\hline Negative & $103(28)$ & $270(72)$ & & $105(24)$ & $334(76)$ & & $230(52)$ & $209(48)$ & \\
\hline Positive & $45(20)$ & $177(80)$ & 0.045 & $37(15)$ & $213(85)$ & 0.004 & $67(27)$ & $183(73)$ & $<0.001$ \\
\hline \multicolumn{10}{|l|}{ PAM50 } \\
\hline Basal like & $19(30)$ & $44(70)$ & & $7(13)$ & $48(87)$ & & $41(75)$ & $14(25)$ & \\
\hline Luminal B & $39(30)$ & $90(70)$ & & $19(17)$ & $93(83)$ & & $53(47)$ & $59(53)$ & \\
\hline HER2 enriched & $20(34)$ & $38(66)$ & & $6(12)$ & $45(88)$ & & $35(69)$ & $16(31)$ & \\
\hline Luminal A & $75(22)$ & 267 (78) & & $52(19)$ & $229(81)$ & & $96(34)$ & $185(66)$ & \\
\hline Normal like & $11(18)$ & $49(82)$ & 0.070 & $13(30)$ & $31(70)$ & 0.164 & $12(27)$ & $32(73)$ & $<0.001$ \\
\hline
\end{tabular}

Pearson's $\chi^{2}$ test was used. IP6K, inositol hexakisphosphate kinase; PI3K, phosphatidylinositol 3 kinase; Akt, protein kinase B; mTOR, mechanistic target of rapamycin.

IP6K2 expression predicted better outcome than low IP6K2 expression (HR: $0.45,95 \% \mathrm{CI}$ : $0.27-0.76, \mathrm{P}=0.0026$ and multivariable HR: 0.38, 95\% CI: 0.21-0.68, $\mathrm{P}=0.0011$, Fig. $1 \mathrm{C})$. Likewise, the distant recurrence-free interval among these patients did not differ based on the IP6K1 levels (univariable $\mathrm{P}=0.60$ and multivariable $\mathrm{P}=0.73$, Fig. 1D).

Similar results were obtained in the TCGA cohort, although no treatment data was available and overall survival was used as end point. High IP6K2 expression indicated better prognosis in univariable $(\mathrm{P}=0.013)$ but not in multivariable analysis correcting for node-, ER-, PgR-, HER2- and TP53 status $(\mathrm{P}=0.21)$, whereas IP6K1 did not have prognostic value (Fig. 1E and F). Subgrouping on TP53 mutational status indicated the importance of a functional TP53 for IP6K2 to be a prognostic biomarker in the TCGA cohort (Table III). No TP53 mutation data was available in the other cohorts.

Roles of IP6K1 and IP6K2 diverge in relation to cancer-related genes at 3p21.31. The chromosomal location of IP6K1 and IP6K2 is at a gene-dense region including 
Table III. IP6K2 and IP6K1 gene expression from RNA sequencing and TP53 status in The Cancer Genome Atlas cohort.

\begin{tabular}{|c|c|c|c|c|c|c|}
\hline \multirow[b]{2}{*}{ Variable } & \multicolumn{3}{|c|}{ TP53 wt $(\mathrm{n}=799)$} & \multicolumn{3}{|c|}{ TP53 mutated $(\mathrm{n}=300)$} \\
\hline & HR & $95 \% \mathrm{CI}$ & P-value & HR & $95 \%$ CI & P-value \\
\hline \multicolumn{7}{|c|}{ IP6K2 (Q1 vs. Q2-4) } \\
\hline Univariable & 0.49 & $0.32-0.75$ & $<0.01$ & 0.84 & $0.48-1.48$ & 0.55 \\
\hline Multivariable & 0.51 & $0.28-0.94$ & 0.03 & 1.40 & $0.63-3.11$ & 0.41 \\
\hline \multicolumn{7}{|c|}{ IP6K1 (Q1 vs. Q2-4) } \\
\hline Univariable & 0.80 & $0.52-1.24$ & 0.32 & 0.92 & $0.52-1.62$ & 0.76 \\
\hline Multivariable & 0.89 & $0.46-1.72$ & 0.73 & 1.33 & $0.58-3.05$ & 0.51 \\
\hline
\end{tabular}

Table IV. Genes associated with cancer at the chromosomal region 3p.21.31.

Gene

Functions

$\begin{array}{ll}\text { SETD2 } & \text { Tumor suppressor gene coding a histone methyltransferase involved in transcription. Interacts with } \\ & \text { p53 and regulates its downstream genes. } \\ \text { PTPN23 } & \text { Tumor suppressor gene coding a tyrosine phosphatase suppressing tumor cell motility and invasion. } \\ \text { CDC25A } & \text { Oncogene coding a phosphatase, activating CDK2 in G1 to S phase transition. } \\ \text { PLXNB1 } & \text { Tumor suppressor gene coding a cell-surface receptor for semaphorin, controlling cell adhesion. } \\ \text { IP6K2 } & \text { Potential tumor suppressor gene coding a kinase involved in cell adhesion and p53-regulated apoptosis } \\ & \text { and through generation of the Akt inhibitor IP7. } \\ \text { RHOA } & \text { Oncogene coding a Ras super family member regulating cell motility and invasion. } \\ \text { IP6K1 } & \text { Gene coding a kinase involved in } \alpha \text {-actinin and FAK regulated cell migration. Potential role in cancer } \\ & \text { through generation of the Akt inhibitor IP7. } \\ \text { RASSF1 } & \text { Tumor suppressor gene coding the Ras-association domain family } 1 \text { protein, downregulated by Akt, } \\ & \text { inhibiting accumulation of cyclin D1 and induces cell cycle arrest. }\end{array}$

several genes with expected impact on cancer development (Fig. 2 and Table IV). We tested gene expression of the IP6Ks in relation to six closely located genes and clinical biomarkers in a multivariable Cox regression analysis in three cohorts (Table V). In the Swedish low-risk- and the Dutch cohort IP6K2 expression remained a protective factor, with a significantly reduced risk of distant recurrence (Swedish low risk: HR: 0.54, 95\% CI: 0.32-0.90, $\mathrm{P}=0.018$, Dutch: HR: 0.29, 95\% CI: $0.15-0.56, \mathrm{P}=0.0003)$, whereas high levels of IP6K1 significantly increased the risk of distant recurrence (Swedish low risk: HR: 2.07, 95\% CI: 1.07-4.02, $\mathrm{P}=0.032$, Dutch: HR: $2.20,95 \%$ CI: $1.02-4.75, \mathrm{P}=0.045)$.

IP6K1 and IP6K2 protein expression. Cytoplasmic and nuclear protein detection was successful in 731 and 724 tumors for IP6K1 and IP6K2, respectively. No significant prognostic value of IP6Ks in the cytoplasm was detected in systemically untreated patients (Fig. S3A and B). However, cytoplasmic IP6K 1 tended to indicate a worse prognosis with higher levels of expression $(\mathrm{P}=0.080)$ in the univariate analysis. Therefore, we divided the IP6K1 expression in three groups; low, medium and high, where a worse prognosis was seen with increasing expression in the univariable analysis (HR: 1.52, 95\% CI: $1.07-2.16, \mathrm{P}=0.019)$, and a trend in the multivariable analysis correcting for ER, PgR and HER2 status and tumor size (HR: 1.39, 95\% CI: 0.95-2.05, P=0.093, Fig. 3). No significant prognostic value was detected with nuclear expression; however, a minor trend of worse prognosis was seen in patients with tumors lacking IP6K in the nucleus (Fig. S3C and D).

Testing protein expression of all tumors in relation to clinicopathological and PI3K/Akt/mTOR-pathway variables IP6K2 cytoplasmic expression was significantly higher in tumors with high levels of cytoplasmic p-Akt $(\mathrm{P}=0.0044)$ and cytoplasmic p-S6K ( $\mathrm{P}=0.00027$, Table I). IP6K2 nuclear positivity associated with small tumors $(\mathrm{P}=0.00084)$ and $\mathrm{p}$-Akt in the nucleus $(\mathrm{P}=0.0022)$. IP6K1 cytoplasmic expression associated with HER2 overexpression $(\mathrm{P}=0.00049)$, cytoplasmic p-Akt $(\mathrm{P}<0.00001)$ and cytoplasmic p-S6K $(\mathrm{P}=0.00004$, Table II). IP6K1 nuclear positivity associated strongly with small tumor size, ER, PgR and the PI3K/Akt/mTOR-pathway markers p-Akt and p-S6K in the nucleus, as well as with the PAM50 luminal molecular subtype. IP6K1 and IP6K2 protein expression were highly associated in cytoplasm $(\mathrm{P}=0.0011)$ and in nuclei $(\mathrm{P}<0.00001)$. 
Table V. Distant recurrence-free interval analyzed by multivariable Cox regression.

\begin{tabular}{|c|c|c|c|c|c|c|c|c|c|}
\hline \multirow[b]{2}{*}{ Variable } & \multicolumn{3}{|c|}{ Swedish low risk $(n=261)$} & \multicolumn{3}{|c|}{ Dutch $(n=165)$} & \multicolumn{3}{|c|}{ TCGA $(n=340)$} \\
\hline & HR & $95 \% \mathrm{CI}$ & P-value & HR & $95 \% \mathrm{CI}$ & P-value & HR & $95 \% \mathrm{CI}$ & P-value \\
\hline SETD2 & 1.01 & $0.54-1.89$ & 0.97 & 0.54 & 0.29-0.99 & 0.05 & 0.98 & $0.47-2.02$ & 0.95 \\
\hline PTPN23 & 0.73 & $0.44-1.23$ & 0.24 & 1.01 & $0.49-2.06$ & 0.98 & 1.56 & $0.61-4.00$ & 0.35 \\
\hline CDC25A & 1.25 & $0.69-2.26$ & 0.46 & 1.21 & $0.63-2.33$ & 0.56 & 1.45 & $0.66-3.20$ & 0.36 \\
\hline PLXNB1 & 1.33 & $0.73-2.42$ & 0.35 & 0.84 & $0.43-1.65$ & 0.61 & 1.21 & $0.50-2.94$ & 0.67 \\
\hline IP6K2 & 0.54 & $0.32-0.90$ & 0.02 & 0.29 & $0.15-0.56$ & $<0.01$ & 0.66 & $0.29-1.50$ & 0.32 \\
\hline RHOA & 1.40 & $0.73-2.69$ & 0.31 & 0.77 & $0.41-1.43$ & 0.41 & 1.10 & $0.44-2.77$ & 0.84 \\
\hline IP6K1 & 2.07 & $1.07-4.02$ & 0.03 & 2.20 & $1.02-4.75$ & 0.05 & 1.69 & $0.61-4.65$ & 0.31 \\
\hline RASSF1 & 0.64 & $0.38-1.07$ & 0.09 & 1.73 & $0.88-3.37$ & 0.11 & 0.89 & $0.41-1.94$ & 0.77 \\
\hline ER & 0.60 & $0.29-1.24$ & 0.17 & 1.24 & $0.61-2.49$ & 0.55 & 0.92 & $0.26-3.19$ & 0.89 \\
\hline $\mathrm{PgR}$ & 2.00 & $1.11-3.59$ & 0.02 & - & - & - & 1.09 & $0.37-3.25$ & 0.87 \\
\hline HER2 & 2.41 & $1.21-4.81$ & 0.01 & 3.43 & $1.78-6.62$ & $<0.01$ & 0.78 & $0.30-1.97$ & 0.59 \\
\hline Node status & - & - & - & 1.56 & $0.81-3.00$ & 0.19 & 1.97 & $1.00-3.87$ & 0.05 \\
\hline Tumor size & 2.48 & $1.50-4.09$ & $<0.01$ & - & - & - & - & - & - \\
\hline
\end{tabular}

Analysis of 3p.21.31 gene expression and clinicopathological variables in tumors from systemically untreated patients in the Swedish low-risk and Dutch cohorts, and overall survival of patients with unknown systemic treatment regimen in The Cancer Genome Atlas cohort. First quartile in gene-expression variables, size $<20 \mathrm{~mm}, \mathrm{ER}, \mathrm{PgR}, \mathrm{HER} 2$ and node negativity were used as reference with HR 1.0 . Risk is presented as HR with a $95 \%$ CI. CI, confidence interval; HR, hazard ratio.

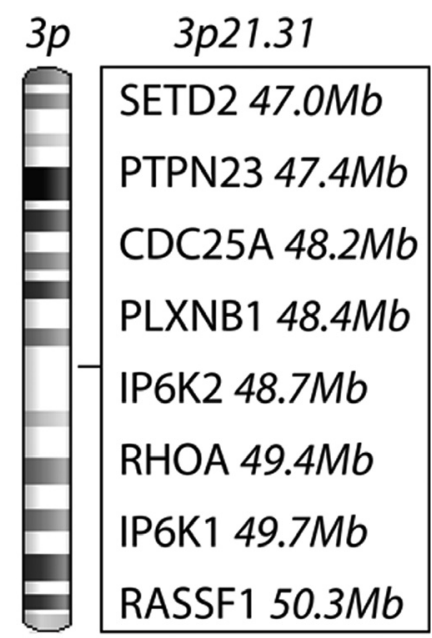

Figure 2. 3p21.31 region with genes commonly deregulated in cancer. In a highly altered chromosomal region, six genes with the nearest location to $I P 6 K 2$ and IP6K1 that had been previously suggested to be deregulated in cancer were selected. The genes are presented in order of chromosomal location. IP6K, inositol hexakisphosphate kinase.

\section{Discussion}

In this study we present data on IP6K1 and IP6K2 in tumors from three large sets of patients with follow up after primary breast cancer. We investigated the prognostic potential of these genes because of their coupling to the PI3K/Akt/mTOR pathway that has been previously studied in our group. Recently reviewed results are varying and exclusively generated from in vitro and animal studies (28).

Previous studies have reported both common and separate roles for the two kinases. Both are important for

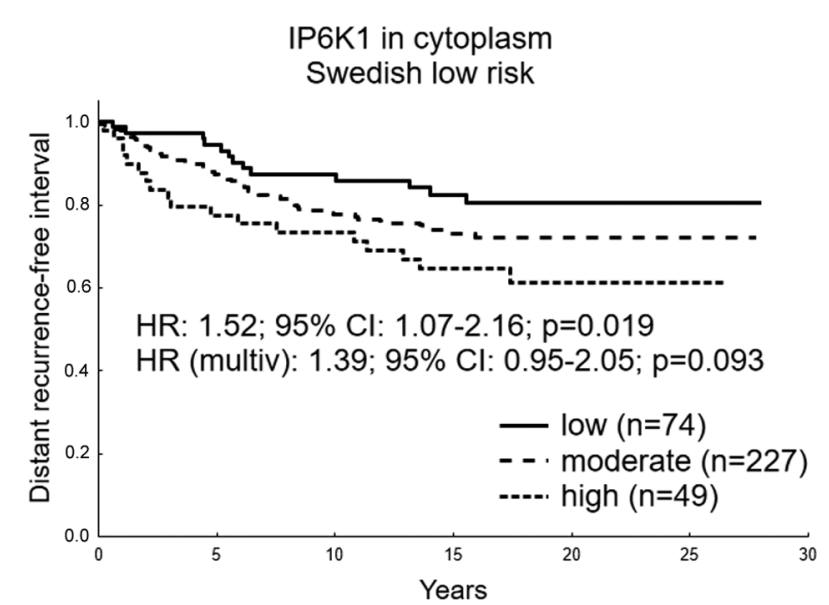

Figure 3. IP6K1 cytoplasmic protein expression in three groups. Prognostic data were produced from systemically untreated patients with primary tumors of the Swedish low-risk breast cancer cohort. The multivariable Cox proportional hazard model corrected for tumor size, estrogen receptor, progesterone receptor and HER2 status. IP6K, inositol hexakisphosphate kinase; HR, hazard ratio; multiv, multivariate.

the generation of IP7 and cell migration. IP6K2 is most prominent in apoptosis in a variety of cells and more often mentioned in association with cancer, while IP6K1 is reported to be a kinase important for insulin secretion in pancreas $(11,29,30)$. The IP6Ks are known to interfere with the PI3K/Akt/mTOR pathway through generation of the Akt inhibitor IP7 (3). IP6K1 and IP6K 2 gene expression as well as protein nuclear expression associated here with PI3K/Akt/mTOR activity in the nucleus, not in the cytoplasm. However, high cytoplasmic protein expression of the IP6Ks associated with an active PI3K/Akt/mTOR 
pathway in the cytoplasm. This was not in line with the expected effect of IP6Ks on the PI3K/Akt/mTOR activity, thus reflecting that other factors may be involved.

For IP6K2, the hypothesized protective role in breast cancer was supported in gene-expression analyses in three independent breast cancer cohorts of which two had systemically untreated patients. Studies point out IP6K 2 as a potential tumor suppressor. Morrison et al $(12,13)$ showed that cells with overexpressed IP6K 2 had a better response to radiation treatment than controls and IP6K2 K-O mice exposed to an oral carcinogen developed oral cancer four times more often than controls. Interestingly, the protective role of IP6K2 remained true only when the TP53 was intact in the TCGA cohort, suggesting that the function of IP6K 2 as tumor suppressor is over-ruled by the oncogenic features generated by TP53 mutation. The p53 expression is regulated by IP7 through catalytically active IP6K and in addition nuclear IP6K2 binds p53 and controls the transcription towards cell repair inhibition and apoptosis activation (11,31). We suggest that in the TP53 mutated cells, this regulation has no effect, as we do not see a prognostic effect of IP6K 2 in patients with TP53 mutated tumors.

The IP6K1 and IP6K2 genes are located closely together on $3 \mathrm{p} 21.31$, with several other genes commonly deregulated in breast cancer (7). Results seen with gene expression could reflect characters of other genes located close to the IP6Ks. Therefore, we searched the region and found six cancer-related genes of interest, namely; SETD2 (32-34), PTPN23 (35), CDC25A (36), PLXNB1 (37), RHOA $(38,39)$, and RASSF1 $(40,41)$. Interestingly, IP6K1 and IP6K2 gene expression show consistent results in multivariable tests of prognostic value in the two cohorts with systemically untreated patients and tendencies in the same direction in the TCGA cohort. Correcting for the expression of the six genes and clinical biomarkers, the IP6K2 decreased the risk of recurrence, as expected of a tumor suppressor gene, and IP6K1 increased the risk of recurrence, as expected of an oncogene. Apart from the previously known prognostic factors; HER2, tumor size and node status, that came out significant in the analysis, only SETD2 indicated a significant prognostic value as tumor suppressor in one cohort. These results suggest that gene-expression analysis can be a useful method to detect prognostic value of individual genes in this gene-dense region.

Analyzing the molecular profile of the IP6K1/2 loci in the large cohort TCGA the mutational burden in these genes was very low. Frequent copy-number variation with more loss than amplification was seen. Copy number and gene expression shows high degree of association for both genes. However, gene expression can be additionally regulated (23). In squamous cell carcinoma of head and neck no promoter methylation of the CDC25A gene was found, while this was frequent in other genes in the region, such as RASSF1A (6).

IP6K 2 protein localization has been explored in functional studies showing that the heat-shock protein HSP90, which often is active in tumor cells, binds directly to IP6K2, not IP6K1, and inhibits its nuclear translocation (42). The nuclear IP6K2 binds p53 and direct the response of DNA damage towards apoptosis rather than cell cycle arrest and repair $(10,11)$. Apoptotic functions of IP6K2 have also been described in neuronal cells (43-45). In our study we detect no prognostic value of
IP6K2 protein levels, although nuclear IP6K2 was more common in small tumors and a minor trend of worse prognosis when tumors lack nuclear IP6K2 was noticed. Localized to the cytoplasmic compartment of the tumor cells IP6K1 tends to take an oncogenic role, and significantly when further dividing the expression in three groups, indicating worse prognosis. This is in line with previous findings describing that IP6K1 is a driver of cell migration $(30,46,47)$. In addition, we found high IP6K1 protein expression in the cytoplasm to be more common in HER2-positive disease and associated with high activity in the PI3K/Akt/mTOR pathway. Nuclear IP6K1 had no significant prognostic value, however in contrast to when found in the cytoplasm the nuclear IP6K1 was more common in small tumors and ER -and PgR positive tumors.

Data presented here represents new insight in the role of the IP6K1 and IP6K 2 as prognostic biomarkers in breast cancer. Gene expression of IP6K2 was the most prominent prognostic marker, demonstrating its protective role in independent cohorts. IP6K1 stood out as an independent prognostic marker of worse outcome in relation to other cancer-related genes on $3 \mathrm{p} 21.31$. Targeting the IP6Ks has potential as breast cancer treatment, although precise selection of patient groups and isoform specific molecules are of importance as the IP6K1 and IP6K 2 seem to diverge in breast cancer.

\section{Acknowledgements}

The authors would like to thank Mrs. Birgitta Holmlund and Mrs. Birgit Olsson, both technicians (Linköping University, Linköping, Sweden), and Dr Lambert Skoog (Karolinska Institute, Stockholm, Sweden), for technical assistance and assessment of clinical biomarkers, respectively.

\section{Funding}

The present study was funded by the Swedish Cancer Society (grant no. 17-0479; to OS), the Region of Östergötland (grant no. LIO-795201; to OS), the Percy Falk Foundation (grant no. 2017-02-10; to JS) and the Oncology Clinic in Linköping Research Fund (grant no. 2019-10-29; to JS).

\section{Availability of data and materials}

The data from the Swedish cohort are not publicly available as the study participants did not consent to sharing their data in a public repository but are available from the corresponding author on reasonable request. The Dutch public dataset analyzed in the current study is available at http://bioinformatics.nki.nl/data.php. The TCGA clinical and genomic data are publicly available from the open-access resource for cancer genomics, cBioPortal (https://www.cbioportal.org/).

\section{Authors' contributions}

OS and JS secured funding. JS, AB, RL and OS conceived the study, and participated in the study design and coordination. JS, AB and RL conducted the experiments. JS, LL, GPT and OS conducted the data analyses and confirm the authenticity of all raw data. TF and BN initiated the clinical trial, and collected patient material and follow-up data for the Swedish 
cohort. All authors read the manuscript drafts and contributed edits. All authors read and approved the final manuscript.

\section{Ethics approval and consent to participate}

All procedures performed in studies involving human participants were in accordance with the ethical standards of the institutional and national research committee and with the 1964 Helsinki Declaration and its later amendments or comparable ethical standards. Ethical approval for the Swedish cohort was obtained from the Karolinska Institute Ethics Council, with approved amendments 02-01-2003 and 10-17-2017. According to the ethical approval, informed consent from the Swedish patients was not required.

\section{Patient consent for publication}

Not applicable.

\section{Competing interests}

The authors declare that they have no competing interests.

\section{References}

1. Guerrero-Zotano A, Mayer IA and Arteaga CL: PI3K/AKT/ mTOR: Role in breast cancer progression, drug resistance, and treatment. Cancer Metastasis Rev 35: 515-524, 2016.

2. Paplomata E and O'Regan R: The PI3K/AKT/mTOR pathway in breast cancer: Targets, trials and biomarkers. Ther Adv Med Oncol 6: 154-166, 2014

3. Chakraborty A, Koldobskiy MA, Bello NT, Maxwell M, Potter JJ, Juluri KR, Maag D, Kim S, Huang AS, Dailey MJ, et al: Inositol pyrophosphates inhibit akt signaling, thereby regulating insulin sensitivity and weight gain. Cell 143: 897-910, 2010.

4. Luo HR, Huang YE, Chen JC, Saiardi A, Iijima M, Ye K, Huang Y, Nagata E, Devreotes P and Snyder SH: Inositol pyrophosphates mediate chemotaxis in dictyostelium via pleckstrin homology domain-PtdIns(3,4,5)P3 interactions. Cell 114: 559-572, 2003.

5. Saiardi A, Erdjument-Bromage H, Snowman AM, Tempst P and Snyder SH: Synthesis of diphosphoinositol pentakisphosphate by a newly identified family of higher inositol polyphosphate kinases. Curr Biol 9: 1323-1326, 1999.

6. Ghosh S, Ghosh A,Maiti GP,Alam N,Roy A,Roy B, Roychoudhury S and Panda CK: Alterations of 3p21.31 tumor suppressor genes in head and neck squamous cell carcinoma: Correlation with progression and prognosis. Int J Cancer 123: 2594-2604, 2008.

7. Ching HC, Naidu R, Seong MK, Har YC and Taib NA: Integrated analysis of copy number and loss of heterozygosity in primary breast carcinomas using high-density SNP array. Int J Oncol 39: 621-633, 2011

8. Manning BD and Cantley LC: AKT/PKB signaling: Navigating downstream. Cell 129: 1261-1274, 2007.

9. Jadav RS, Kumar D, Buwa N, Ganguli S, Thampatty SR Balasubramanian $\mathrm{N}$ and Bhandari R: Deletion of inositol hexakisphosphate kinase 1 (IP6K1) reduces cell migration and invasion, conferring protection from aerodigestive tract carcinoma in mice. Cell Signal 28: 1124-1136, 2016.

10. Rao F, Cha J, Xu J, Xu R, Vandiver MS, Tyagi R, Tokhunts R, Koldobskiy MA, Fu C, Barrow R, et al: Inositol pyrophosphates mediate the DNA-PK/ATM-p53 cell death pathway by regulating CK2 phosphorylation of Tti1/Tel2. Mol Cell 54: 119-132, 2014.

11. Koldobskiy MA, Chakraborty A, Werner JK Jr, Snowman AM, Juluri KR, Vandiver MS, Kim S, Heletz S and Snyder SH: p53-Mediated apoptosis requires inositol hexakisphosphate kinase-2. Proc Natl Acad Sci USA 107: 20947-20951, 2010.

12. Morrison BH, Bauer JA, Hu J, Grane RW, Ozdemir AM, Chawla-Sarkar M, Gong B, Almasan A, Kalvakolanu DV and Lindner DJ: Inositol hexakisphosphate kinase 2 sensitizes ovarian carcinoma cells to multiple cancer therapeutics. Oncogene 21 : 1882-1889, 2002.
13. Morrison BH, Haney R, Lamarre E, Drazba J, Prestwich GD and Lindner DJ: Gene deletion of inositol hexakisphosphate kinase 2 predisposes to aerodigestive tract carcinoma. Oncogene 28: 2383-2392, 2009

14. Bostner J, Karlsson E, Pandiyan MJ, Westman H, Skoog L, Fornander T, Nordenskjöld B and Stål O: Activation of akt, mTOR, and the estrogen receptor as a signature to predict tamoxifen treatment benefit. Breast Cancer Res Treat 137: 397-406, 2013.

15. Karlsson E, Perez-Tenorio G, Amin R, Bostner J, Skoog L, Fornander T, Sgroi DC, Nordenskjöld B, Hallbeck AL and Stål O: The mTOR effectors 4EBP1 and S6K2 are frequently coexpressed, and associated with a poor prognosis and endocrine resistance in breast cancer: A retrospective study including patients from the randomised stockholm tamoxifen trials. Breast Cancer Res 15: R96, 2013.

16. Bostner J, Karlsson E, Eding CB, Perez-Tenorio G, Franzén H, Konstantinell A, Fornander T, Nordenskjöld B and Stål O: S6 kinase signaling: Tamoxifen response and prognostic indication in two breast cancer cohorts. Endocr Relat Cancer 22: 331-343, 2015.

17. Rutqvist LE, Johansson H; Stockhol Breast Cancer Study Group: Long-Term follow-up of the randomized stockholm trial on adjuvant tamoxifen among postmenopausal patients with early stage breast cancer. Acta Oncol 46: 133-145, 2007.

18. Jerevall PL, Jansson A, Fornander T, Skoog L, Nordenskjöld B and Stål O: Predictive relevance of HOXB13 protein expression for tamoxifen benefit in breast cancer. Breast Cancer Res 12: R53, 2010.

19. Khoshnoud MR, Löfdahl B, Fohlin H, Fornander T, Stål O, Skoog L, Bergh J and Nordenskjöld B: Immunohistochemistry compared to cytosol assays for determination of estrogen receptor and prediction of the long-term effect of adjuvant tamoxifen. Breast Cancer Res Treat 126: 421-430, 2011.

20. Bostner J, Skoog L, Fornander T, Nordenskjöld B and Stål O: Estrogen receptor-alpha phosphorylation at serine 305, nuclear p21-activated kinase 1 expression, and response to tamoxifen in postmenopausal breast cancer. Clin Cancer Res 16: 1624-1633, 2010.

21. McShane LM, Altman DG, Sauerbrei W, Taube SE, Gion M and Clark GM; Statistics Subcommittee of the NCI-EORTC Working Group on Cancer Diagnostics: Reporting recommendations for tumour MARKer prognostic studies (REMARK). Br J Cancer 93: 387-391, 2005

22. van de Vijver MJ, He YD, van't Veer LJ, Dai H, Hart AA, Voskuil DW, Schreiber GJ, Peterse JL, Roberts C, Marton MJ, et al: A gene-expression signature as a predictor of survival in breast cancer. N Engl J Med 347: 1999-2009, 2002.

23. Cancer Genome Atlas Research Network, Weinstein JN Collisson EA, Mills GB, Shaw KR, Ozenberger BA, Ellrott K, Shmulevich I, Sander C and Stuart JM: The cancer genome atlas pan-cancer analysis project. Nat Genet 45: 1113-1120, 2013.

24. Gao J, Aksoy BA, Dogrusoz U, Dresdner G, Gross B, Sumer SO, Sun Y, Jacobsen A, Sinha R, Larsson E, et al: Integrative analysis of complex cancer genomics and clinical profiles using the cBioPortal. Sci Signal 6: pl1, 2013.

25. Spratt DE, Chan T, Waldron L, Speers C, Feng FY, Ogunwobi OO and Osborne JR: Racial/Ethnic disparities in genomic sequencing. JAMA Oncol 2: 1070-1074, 2016

26. Esserman LJ, Yau C, Thompson CK, van't Veer LJ, Borowsky AD, Hoadley KA, Tobin NP, Nordenskjöld B and Fornander T: Use of molecular tools to identify patients with indolent breast cancers with ultralow risk over 2 decades. JAMA Oncol 3: 1503-1510, 2017.

27. Parker JS, Mullins M, Cheang MC, Leung S, Voduc D, Vickery T, Davies S, Fauron C, He X, Hu Z, et al: Supervised risk predictor of breast cancer based on intrinsic subtypes. J Clin Oncol 27: 1160-1167, 2009.

28. Chakraborty A: The inositol pyrophosphate pathway in health and diseases. Biol Rev Camb Philos Soc 93: 1203-1227, 2018.

29. Illies C, Gromada J, Fiume R, Leibiger B, Yu J, Juhl K, Yang SN, Barma DK, Falck JR, Saiardi A, et al: Requirement of inositol pyrophosphates for full exocytotic capacity in pancreatic beta cells. Science 318: 1299-1302, 2007.

30. Fu C, Xu J, Cheng W, Rojas T, Chin AC, Snowman AM, Harraz MM and Snyder SH: Neuronal migration is mediated by inositol hexakisphosphate kinase 1 via $\alpha$-actinin and focal adhesion kinase. Proc Natl Acad Sci USA 114: 2036-2041, 2017.

31. Gu C, Nguyen HN, Ganini D, Chen Z, Jessen HJ, Gu Z, Wang H and Shears SB: KO of 5-insP7 kinase activity transforms the HCT116 colon cancer cell line into a hypermetabolic, growth-inhibited phenotype. Proc Natl Acad Sci USA 114: 11968-11973, 2017. 
32. Al Sarakbi W, Sasi W, Jiang WG, Roberts T, Newbold RF and Mokbel K: The mRNA expression of SETD2 in human breast cancer: Correlation with clinico-pathological parameters. BMC Cancer 9: 290, 2009.

33. Roberti A, Dobay MP, Bisig B, Vallois D, Boéchat C, Lanitis E, Bouchindhomme B, Parrens MC, Bossard C and Quintanilla-Martinez L: Type II enteropathy-associated T-cell lymphoma features a unique genomic profile with highly recurrent SETD2 alterations. Nat Commun 7: 12602, 2016.

34. Duns G, van den Berg E, van Duivenbode I, Osinga J, Hollema H, Hofstra RM and Kok K: Histone methyltransferase gene SETD2 is a novel tumor suppressor gene in clear cell renal cell carcinoma. Cancer Res 70: 4287-4291, 2010.

35. Zhang S, Fan G, Hao Y, Hammell M, Wilkinson JE and Tonks NK: Suppression of protein tyrosine phosphatase N23 predisposes to breast tumorigenesis via activation of FYN kinase. Genes Dev 31: 1939-1957, 2017.

36. Sadeghi H, Golalipour M, Yamchi A, Farazmandfar T and Shahbazi M: CDC25A pathway toward tumorigenesis: Molecular targets of CDC25A in cell-cycle regulation. J Cell Biochem 120: 2919-2928, 2019.

37. Malik MF, Ye L and Jiang WG: Reduced expression of semaphorin 4D and plexin-B in breast cancer is associated with poorer prognosis and the potential linkage with oestrogen receptor. Oncol Rep 34: 1049-1057, 2015.

38. Zhang C, Wang HJ, Bao QC, Wang L, Guo TK, Chen WL, Xu LL, Zhou HS, Bian JL, Yang YR, et al: NRF2 promotes breast cancer cell proliferation and metastasis by increasing RhoA/ROCK pathway signal transduction. Oncotarget 7: 73593-73606, 2016.

39. Jeong D, Park S, Kim H, Kim CJ, Ahn TS, Bae SB, Kim HJ, Kim TH, Im J, Lee MS, et al: RhoA is associated with invasion and poor prognosis in colorectal cancer. Int J Oncol 48: 714-722, 2016.

40. Agathanggelou A, Cooper WN and Latif F: Role of the ras-association domain family 1 tumor suppressor gene in human cancers. Cancer Res 65: 3497-3508, 2005.
41. Blanchard TG, Lapidus R, Banerjee V, Bafford AC, Czinn SJ, Ahmed $\mathrm{H}$ and Banerjee $\mathrm{A}$ : Upregulation of RASSF1A in colon cancer by suppression of angiogenesis signaling and akt activation. Cell Physiol Biochem 48: 1259-1273, 2018.

42. Chakraborty A, Koldobskiy MA, Sixt KM, Juluri KR, Mustafa AK, Snowman AM, van Rossum DB, Patterson RL and Snyder SH: HSP90 regulates cell survival via inositol hexakisphosphate kinase-2. Proc Natl Acad Sci USA 105: 1134-1139, 2008

43. Nagata E, Saiardi A, Tsukamoto H, Okada Y, Itoh Y, Satoh T, Itoh J, Margolis RL, Takizawa S, Sawa A and Takagi S: Inositol hexakisphosphate kinases induce cell death in huntington disease. J Biol Chem 286: 26680-26686, 2011.

44. Nagata E, Nonaka T, Moriya Y, Fujii N, Okada Y, Tsukamoto H, Itoh J, Okada C, Satoh T, Arai T, et al: Inositol hexakisphosphate kinase 2 promotes cell death in cells with cytoplasmic TDP-43 aggregation. Mol Neurobiol 53: 5377-5383, 2016.

45. Moriya Y, Nagata E, Fujii N, Satoh T, Ogawa H, Hadano S and Takizawa S: Inositol hexakisphosphate kinase 2 is a presymptomatic biomarker for amyotrophic lateral sclerosis. Tokai J Exp Clin Med 42: 13-18, 2017.

46. Rao F, Xu J, Fu C, Cha JY, Gadalla MM, Xu R, Barrow JC and Snyder SH: Inositol pyrophosphates promote tumor growth and metastasis by antagonizing liver kinase B1. Proc Natl Acad Sci USA 112: 1773-1778, 2015.

47. Izaguirre G, Aguirre L, Hu YP, Lee HY, Schlaepfer DD, Aneskievich BJ and Haimovich B: The cytoskeletal/non-muscle isoform of alpha-actinin is phosphorylated on its actin-binding domain by the focal adhesion kinase. J Biol Chem 276: 28676-28685, 2001.

This work is licensed under a Creative Commons

Attribution-NonCommercial-NoDerivatives 4.0 International (CC BY-NC-ND 4.0) License. 